\title{
Correction to: Measuring short-term risk of initial public offering of equity securities: a hybrid Bayesian and Data-Envelopment-Analysis-based approach
}

\author{
Shabnam Sorkhi ${ }^{1}$ (D) . Joseph C. Paradi ${ }^{1}$
}

(c) Springer Science+Business Media, LLC, part of Springer Nature 2019

\section{Correction to: Annals of Operations Research https://doi.org/10.1007/s10479-019-03439-0}

This erratum is published as several typo errors during proofing stage were overlooked such as indents, important upper case/lower cases, or elimination of superscripts in, e.g., 90th, etc.

Original article has been updated thus.

Publisher's Note Springer Nature remains neutral with regard to jurisdictional claims in published maps and institutional affiliations.

The original article can be found online at https://doi.org/10.1007/s10479-019-03439-0.

Shabnam Sorkhi

shabnam.sorkhi@mail.utoronto.ca

Joseph C. Paradi

paradi@mie.utoronto.ca

1 The Center for Management of Technology and Entrepreneurship, University of Toronto,

200 College St., Toronto, ON M5S 3E5, Canada 